\title{
[ PATRIZIA MAGLI ]
}

Graduada em Filosofia pela Universidade de Florença. Começou sua carreira acadêmica como assistente do professor Umberto Eco em Semiótica na Universidade de Bolonha (1973-1980). Foi pesquisadora assistente e professora de Semiótica na mesma instituição (1980-2000). Desde 2000, leciona Semiótica da Arte e Semiótica do Design na Universidade IUAV de Veneza. Suas pesquisas são em Semiótica do Teatro, Design e Arte Contemporânea.

E-mail: pat.magli@gmail.com

\section{Colete: 0 discreto charme do inatual'}

\section{The vest: the discreet charm of the unactual}

[resumo] 0 colete pode ser considerado um simples acessório? Que tipo de relação engendra com aqueles que o vestem? Qual seu significado na atualidade? Vale lembrar que essa vestimenta pertence, hoje, ao conjunto de coisas obsoletas que se apresentam sem função - ou que a estão progressivamente perdendo. Se moda

[140] significa modo de ser, qual o sentido de vestir um traje "fora de moda"? Estas são questões que pretendemos responder neste artigo. Importante considerar que 0 colete possui uma extraordinária força simbólica e seu charme reside na ambivalência intrínseca que encontramos na relação entre o homem, as coisas e seu tempo. No caso particular do colete, assiste-se, ainda, a uma espécie de oscilação de um traje tipicamente masculino para um traje feminino. De um modo geral, o colete nos convida a refletir sobre o conceito de vestimenta, pois envolve e mobiliza uma notável experiência sensorial.

\section{palavras-chave}

colete; vestimenta; traje; masculino; moda.

[abstract]Can the vest be considered a simple accessory? What kind of relationship does it create with the ones who wear it? What is its meaning nowadays? We should remember that this piece belongs, now, to the group of obsolete things that present no function - or that are progressively losing it. If fashion means a way of being, what is the sense of wearing a garment that is "out of fashion"? These are questions that we intent to answer in this article. It is important to consider that the vest possesses an extraordinary symbolic strength and its charm resides on the intrinsic ambivalence that we find in the relationship between men, their things and their time. In the particular case of the vest, we see, however, a sort of oscillation from a typically male garment to a female one. In general, the vest invites us to reflect upon the concept of clothing, since it involves and moves a remarkable sensorial experience.

[keywords] vest; clothing; garment; male; fashion. 
Nada sabemos sobre o jovem Werther. Não sabemos se era loiro ou moreno, alto ou baixo, feio ou bonito - sabemos simplesmente que era "jovem". No entanto, existe um detalhe - apenas um - que nos diz algo sobre o seu parecer físico: um colete amarelo sob um fraque azul. Trata-se de um traço cromático que funciona como um operador de individuação, como, por exemplo, o vestidinho vermelho da menina de A Lista de Schindler, de Steven Spielberg (1993), a única cor em um filme inteiramente em preto e branco.

Foi com grande pesar que tive que me desfazer do fraque azul que eu envergava quando dancei pela primeira vez com Carlota, mas, realmente, estava imprestável, escreve Werther para o amigo Guilherme. Mandei, porém, fazer outro exatamente igual: mesma gola, mesmo forro, colete e culote amarelos. Contudo, o efeito não será o mesmo. Não sei... Espero que com o tempo este traje se torne para mim tão querido como o outro (GOETHE, 1995, p. 90).

0 fraque azul e o colete amarelo fazem parte daqueles tênues traços do sensivel que, além do nome, atestam uma permanência, um pouco de perdurar de um indivíduo que nos permite afirmar, no decorrer dos eventos, que estamos sempre diante do mesmo indivíduo. No romance de Goethe, tais traços atestam a continuidade de uma personagem que passa do entusiasmo à desilusão, do desdém ao tédio e, enfim, do desespero à morte:

Estirado e de súbito dorsal, imóvel, perto da janela, estava completamente vestido e calçado, trajando um fraque azul e um colete amarelo (GOETHE, 1995, p. 141).

A última imagem de Werther teve um papel determinante na epidemia de suicidios que se consolidou como um dos efeitos mais trágicos que esse romance provocou nos jovens da época. Muitos, imitando o gesto impulsivo do protagonista da obra, vestiam um fraque azul e um colete amarelo.

Da imensa riqueza fenomenológica de um indivíduo, muitas vezes, a memória seleciona apenas alguns detalhes aparentemente marginais: a consistência da voz, a maneira de ajustar os óculos sobre o nariz, o aroma de um charuto ou um detalhe do traje, como, por exemplo, o colete. Mas o colete é mesmo um simples detalhe? Pode ser realmente considerado um simples acessório, como um cachecol, um chapéu, um lenço ou um par de luvas? Que relação engendra com aqueles que o vestem? Como afirma Barthes (1967), o que no universo da moda chamamos de acessório é, muitas vezes, por antífrase, o essencial. Entretanto, pode-se ainda falar em moda a propósito de colete?

0 fato dessa peça ter se tornado, ao longo dos anos, um objeto obsoleto, e portanto fora de moda, fez com que lhe fosse conferido, paradoxalmente, um valor adjunto, um superávit de sentido. Há certo consenso de que o fim de uma vestimenta é a proteção ou o ornamento. No que diz respeito à moda, cumpre ambas as funções: a motivação de um vestuário fundamenta-se, ao mesmo tempo, na função utilitária e na imitação de um modelo estético (BARTHES, 1967). E, muitas vezes, a segunda prevalece sobre a primeira. Na sua acepção estética, pode-se encontrar hoje um traço da temporalidade. 0 traje atual significa, de fato, um traje do passado e, nesse sentido, é pura evocação: mima a sua própria origem, ou melhor, a evidencia. 0 colete atual não manifesta, portanto, uma funcionalidade, mas pertence ao conjunto de coisas que Orlando chama de "inúteis, envelhecidas ou insólitas". Trata-se daquelas coisas físicas "obsoletas e falecidas" (ORLAND0, 1993, p. 6), daqueles objetos que se apresentam sem função - ou que a estão progressivamente perdendo. Como tais, Orlando ressalta sua extraordinária sorte simbólica em relação à representação de coisas úteis ou novas. Seu destino é evanescer como objetos funcionais para voltar, sucessivamente, sob forma de signos puros.

De forma análoga aos objetos dessuetos, o colete sofreu, ao longo do tempo, uma transformação que tem muito a dizer sobre a relação entre o homem e as coisas. De fato, a capacidade de resistência de uma vestimenta pode sobreviver molecularmente e alterar, no entanto, seu significado, a ponto de tanto a sua função quanto o seu 
sentido originais poderem ser subvertidos. É a transformação à qual uma vestimenta está sujeita no transcorrer das modas, com todas as contradições aparentes, entre os ressurgimentos, as fobias e todas as sedimentações evocativas que, com o tempo, a cobrem e a envolvem. Não é possível, pois, negar ao colete um resíduo de funcionalidade, se considerarmos, sobretudo, as pessoas que ainda o vestem. Porém, sua praticidade atual pressupõe outra funcionalidade perdida, recuperando com prepotência o não funcional. Seu charme reside exatamente na ambivalência intrínseca que abita a relação ente o homem, as coisas e seu tempo. Como alega Orlando (1993, p. 15):

0 tempo consuma as coisas e as destrói, estragando-as e tornando-as irreversiveis, faz com que estas fiquem fora de moda e abandonadas. 0 tempo torna as coisas caras ao hábito e eficazes à ostentação, oferecendo-Ihes ternura enquanto lembranças e autoridade enquanto modelos.

Era uma vez o colete...

0 que é, portanto, essa veste - em italiano, panciotto, ${ }_{1}^{2}$ que deriva de pancia (pança) - que estabelece uma espécie de interface entre a parte de nós que está intimamente conectada ao nosso corpo, à nossa pele, e o que está, ao contrário, exposto ao parecer?

Antes de mais nada, seu valor, entendido enquanto valor estrutural, é o resultado da posição que este ocupa em relação a outras vestimentas, dentro de um sistema de oposições e diferenças que circunscrevem sua funcionalidade e seu caráter diante de outras peças. 0 que funda um sistema de signos é, pois, o papel que cada um deles desenvolve em relação aos outros; é o modo sistemático com que cada signo se aproxima ou se diferencia dos outros. Assim, o colete, conhecido também como gilet ${ }^{3}$ ou gilè, nasce como traje masculino, vestido em cima da camisa e embaixo do paletó. Contrariamente a estes, não possui mangas, faldas e gola. Por outro lado, é decorado com dois ou quatro bolsinhos e pode ser transpassado ou não. Abotoa-se verticalmente pelo lado da frente, onde, de forma diferente do que ocorria antigamente, deixa descoberta parte da camisa e da gravata.

No Ocidente, durante o século XVIII, o colete era feito do mesmo tecido que o paletó ou, de qualquer forma, se harmonizava com este, enquanto a parte posterior era simplesmente revestida e abrigava laços para poder regular o colete segundo o corpo da pessoa. Sucessivamente, mesmo permanecendo estreito na cintura e com seu revestimento simples, a parte posterior foi complementada com um martingale ${ }^{4}$ regulado com uma fivela de metal. Esse dúplice modo de ser do colete, luxuoso na frente e humilde na parte de trás, foi interpretado como um dos sintomas do nascimento da imitação típica do começo do capitalismo sob a pressão de um novo valor social, o "mostrar-se aos outros" (ORLANDO, 1993, p. 117).

Portanto, o colete poderia ser confeccionado com ou sem mangas, mas os tecidos utilizados pela parte da frente deveriam ser, a qualquer custo, preciosos: cetim, seda, brocado, muitas vezes decorados com fios de ouro e prata. Vale lembrar que no século $\mathrm{XVI}$ seu comprimento era tal que o colete chegava quase até o joelho. Aberto na frente, costumava ser fechado com um muitos botões. Assumia forma de cone fechado nas laterais e tinha bolsos cobertos com abas moldadas. Vestia-se sob o giustacuore ou marsina, uma espécie de paletó que descia até o joelho e que ficava aberto para exibir o colete. Com o tempo, este reivindicou autonomia em relação ao paletó, razão pela qual surgiram os coletes bordados, de seda ou veludo, que se tornaram verdadeiros objetos de coleção.

Ele levou a coleção de coletes mais rebuscados: havia coletes cinzentos, brancos, pretos, cor de besouro com reflexos dourados, de lantejoulas, sarapintados, de xale ou gola alta, de gola virada, abotoados até em cima e de botões dourados (BALZAC, 2013).

Todavia, no século XVIII, o tamanho do colete diminui - assumindo uma forma parecida com a atual - e entra no universo das vestimentas cotidianas. 0 colete tinha uma relação tão simbiótica com o homem a ponto de se tornar, por assim dizer, a sua 
sinédoque, o símbolo de suas qualidades morais. Por volta de 1860, em Paris, gilet $\dot{a}$ coeurs usados pelos élégants significava, por extensão, "homem elegante trajado à moda". No final do século, os "elegantes" vestiam calças xadrez e sapatos de verniz copal com polainas cândidas, cândidas como o colete de piquê.

Mas, no início dos anos 1900, o paletó de cidade em tons cinza-chumbo e cinza-ferro abre-se sobriamente pela frente, sobre um colete de pérolas, um plastrão (espécie de gravata larga) de seda cinza e calças de listras brancas e pretas ou, em outros casos, simplesmente cinza. Para a noite, era obrigatório o fraque, vestido sempre com o colete, decorado com cadeados pesados e relógios. Naquele momento, o colete muitas vezes era emblema das qualidades femininas de esposas e namoradas, sendo que aqueles costurados à mão eram muito valorizados e apreciados.

Destacado nos retratos de aristocratas e ricos burgueses entre os séculos XVII e

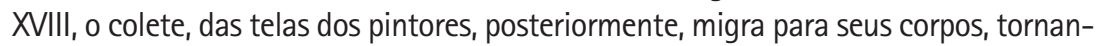
do-se, enfim, objeto de arte. ${ }^{5}$

Entre as duas guerras mundiais, nasce em Londres uma nova filosofia: aquela dos edwardians, ou seja, a filosofia daqueles que seguiam as inovações promovidas pelo Príncipe de Gales. A primeira novidade foi o fato de não abotoar o ultimo botão do colete. Além disso, a veste mostra também uma vocação interclassista. ${ }^{6} 0$ traje de festa, na Sicília dos camponeses, era composto por um par de calças de veludo sem abertura na frente, fechadas com fivelas na altura dos joelhos, e um grande colete (chamado panzera) feito com o mesmo tecido e decorado com uma série de botões de bronze que se vestia debaixo de um casaco de veludo escuro. 0 colete, com seu bolso ornado com o onipresente cadeado do relógio, aparece também debaixo dos paletós da burguesia dos Mastro Don Gesualdo. ${ }^{7}$

\section{0 que o colete guardava secretamente?}

0 colete parece possuir todos os requisitos para almejar a ser o que Barthes (1967) define um "excelente objeto poético". Antes de mais nada porque essa vestimenta envolve e mobiliza uma notável experiência sensorial:

(...) mobiliza com muita variedade todas as qualidades da matéria substância, forma, cor, tactilidade, movimento, apresentação, luminosidade; e depois porque, em contato com o corpo e funcionando ao mesmo tempo como seu substituto e sua cobertura, é ele, certamente, objeto de um investimento muito importante (BARTHES, 1967, p. 238).

A disposição "poética" do colete é atestada pela frequência e pelas qualidades de suas descrições na literatura. De fato, é a estranheza de um colete sobre um coelho branco que leva Alice a segui-lo até sua toca para precipitar, pouco depois, no País das Maravilhas:

Não havia nada de tão extraordinário no fato em si; nem Alice achou assim tão esquisito ouvir o Coelho murmurar consigo mesmo: "Ai, ai! $\mathrm{Ai}$, ai! Vou chegar tarde demais!" (quando pensou sobre isso mais tarde, ocorreu-Ihe que deveria ter se assustado, mas na hora tudo pareceu muito natural); mas quando viu o Coelho tirar um relógio do bolso do colete e conferir as horas, e depois sair em disparada, Alice se levantou num pulo, porque constatou imediatamente que nunca tinha visto um coelho com colete, nem com relógio para tirar do bolso, e, ardendo de curiosidade, correu pelo campo atrás dele, ainda a tempo de vê-lo desaparecer numa grande toca debaixo da cerca (CAROLL, 2012, p. 19).

Nenhuma vestimenta é tão presente na literatura quanto o colete. Quer em textos verbais, quer em textos visuais, ${ }^{8}$ temos o testemunho da relação que este tinha com os sujeitos que o vestiam. Mas é unicamente a escrita que pode fazer reviver o uso pessoal e circunstancial de uma vestimenta do passado - o modo peculiar de usá-lo. No entanto, a mesma escrita mostra apenas uma parte, um fragmento do objeto que estamos descrevendo, focalizado a partir de um determinado ponto de vista. 
Eis, por exemplo, o que se encontra nos bolsos do colete de Gulliver, naufragado no país dos Lilliput. Uma vez capturado o protagonista do romance de Johnatan Swift, estes examinam com cuidado e meticulosidade sua roupa:

(...) no bolso direito do colete encontramos um feixe prodigioso de substâncias brancas e finas, dobradas uma sobre a outra, mais ou menos do tamanho de três homens, amarradas com um cabo forte, e cobertas de sinais negros; os quais, humildemente, consideramos que sejam escritos, sendo cada letra quase do tamanho da metade da palma de uma de nossas mãos. No bolso esquerdo, havia uma espécie de aparelho, da parte de trás do qual se estendiam vinte postes compridos, que lembram a paliçada diante da Corte de vossa Majestade; conjecturamos que é por meio deste aparelho que o Homem-Montanha penteia seus cabelos (SWIFT, 1997, p. 23).

Além das cartas privadas e dos pentes, há de tudo dentro dos bolsos do colete: relógios de arame com cadeados formidáveis, óculos e monóculos, bilhetes comprometedores, cachimbos, moedas e trocado, como relata Italo Svevo (1993) em La coscienza di Zeno. Tendo que procurar alguns cigarros para retribuir o presente de um dos seus colegas de escola, o narrador é obrigado a roubá-los do pai.

No verão, meu pai deixava sobre uma cadeira, na sala de jantar, seu colete, em cujo bolso havia sempre algumas moedas: eu catava aquelas necessárias para adquirir a preciosa caixinha e fumava um cigarro após o outro, todos os dez que ela continha (...) Lembro-me de que meu pai um dia me surpreendeu com o colete dele na mão. Eu, com uma desfaçatez que agora não teria e que ainda hoje me repugna (...) disse-Ihe que fora agredido pela curiosidade de contar os botões de seu colete. Meu pai riu dessa minha disposição para a matemática ou para a alfaiataria, sem perceber que eu tinha os dedos metidos no bolsinho (SVEV0, 1993).

Porém, além disso, o colete serve, em particular, para abrigar e esconder as mãos de quem o veste, como é possivel observar nos retratos do passado. ${ }^{9}$ Vamos procurar entender por que nas páginas seguintes.

\section{Sensações táteis: o corpo, o gesto e o colete}

0 fato de que um traje seja estrito, aderente, largo, macio, afastado, amplo, mede-se a partir do sentido da distância. Distância do corpo. 0 corpo é, nesse caso, o ponto de referência em relação ao qual se exprime a pressão mais ou menos imponente de uma vestimenta: um sobretudo (como aqueles abertos, longos e compridos, sobre os coletes aderentes) pode ficar mais ou menos distante do corpo; um blazer pode ficar mais ou menos aderente; outras peças podem também se livrar do corpo a ponto de se afastar muito dele, como o cachecol; outras ainda podem ficar bem aderentes, como o corset ou o basque. Trata-se de um movimento de contração ou de dilatação. É nesse nível de sensação, afirma Barthes (1967), que se instaura uma espécie de tensividade da vestimenta.

A sensação do colete participa daquela ordem de percepções gerais do corpo humano. Aquelas que nos fazem sentir à vontade ou constrangidos. A consequência dessa dinâmica é que essa alternância tensiva entre o tenso e o relaxado ou, nesse caso, entre o estendido e o distendido, prepara, por sua vez, um percurso que não diz apenas respeito à sensação, mas também ao sentir. Por exemplo, a aderência, como observa Barthes (1967), pode ser facilmente abordada sob uma perspectiva analítica. Quem seguiu esse caminho foi Flügel (1950), que traçou uma tipologia caracterial baseada no grau de constrição do traje, considerado, ao mesmo tempo, uma proteção e uma prisão. Rente ao corpo, mas sem sufocá-lo, o colete torna-se, na literatura, sinônimo de "ficar à vontade", de se "sentir à vontade".

Aderente sem ser muito estreito, secreto sem ser escondido, o colete é o que fica entre o interno e o externo, o visível e o invisível, entre a intimidade e o parecer. Em uma palavra, o colete é um limite: uma fronteira que abre uma relação entre o si e 0 
outro. Tão intimamente perto do corpo, o colete age e retroage, por sua vez, sobre 0 corpo, tecendo, em volta de seus bolsos e de suas fissuras escondidas, ao redor de seus botões, de suas aberturas aparentes, uma densa trama de gestos, que se tornaram, por hábito, quase automáticos. Gestos que fizeram parte de um conjunto de posturas que marcou o modo de ser de reis e cortesãos, de aristocratas, de grandes e pequenos burgueses, de cidadãos e artistas. Trata-se de um tecido de micromovimentos que, ao longo de dois séculos, não apenas fez parte de estilos gestuais, mas do inteiro comportamento não verbal masculino, condicionando-o, modulando-o e desenvolvendo, por assim dizer, uma função suprassegmental, como o tom da voz que, às vezes, desmente as palavras que acedem.

"Giaime - disse a mulher se queixando - se vira você com estes pobres coitados". 0 jovem ordenou ao seu cavalo de desacelerar e, com dois dedos, começou a extrair do bolso do colete, pequenas moedas de bronze e prata. "Para vocês. Tomem!" (DELEDDA, 2013).

\section{0 colete e o "efeito personagem"}

Pleurer dans le gilet de quelqu'un, na França, significa ainda hoje escolher uma pessoa à qual confiar os nossos pesares. A parte para o todo. Trata-se de um procedimento bem conhecido por certa atitude realístico-descritiva. A esse propósito, Jakobson (1966, p. 63) destaca os détails synecdochiques enquanto processo emblemático para a individuação dos personagens: ambientes, objetos, partes do corpo, gestos ou vestimentas contribuem, juntos, para a produção do "efeito personagem".

Porém, mesmo que a escrita tenha maior propensão para os detalhes e fragmentos do mundo sensivel do que para a totalidade dos indivíduos, é verdade que, na realidade, nenhum detalhe ou fragmento acessório é algo destinado a permanecer marginal, fechado em si mesmo. Muito pelo contrário: tem uma ação irradiante sobre a totalidade da qual faz parte.

Qual significado tem hoje, portanto, uma peça do gosto deliciosamente retrô como o colete? Se a moda, como aponta Abruzzese (2001, p. 21), significa modo de ser, qual o sentido de vestir um indumento "fora de moda"? Pode ser, talvez, a tentativa de introduzir dentro da ininterrupta fluidez do presente - para utilizar as palavras do sociólogo - a estaticidade de uma forma de pertencimento, de um modo de ser? "Ser de moda" ou "ser à moda", afirma Abruzzese (2001, p. 7), significa "ser no presente", no flagrante do momento. Mas também a expressão "ser fora de moda", continua o pesquisador, significa uma presença, já que reafirma a forte intimidade entre as formas da moda, tanto aquelas capazes de se impor e triunfar como aquelas que são excluídas. No entanto, o "ser moda" pertence a uma substância sem coesão, a uma espécie de "estado gasoso" (ABRUZZESE, 2001, p. 15). É o lugar da máxima pulsão metamórfica de coisas e de identidades em que se desconfia que, de fato, nada de novo irá acontecer. Ao contrário, onde não existia a espiral da moda, era a mobilidade do ser que encontrava, na estabilidade das roupas e das formas vestimentárias, o suporte sobre o qual pode se movimentar para vivenciar o mundo, para habitá-lo (ABRUZZESE, 2001).

Mas aquela que Abruzzese (2001) chama de "substância gasosa" da moda nada mais é do que a enorme reserva de significados da qual esta dispõe: os significados prontos a serem investidos de outros significantes variados, peculiares. Aquele da moda é um mundo rico, cheio de tempos, de lugares, de circunstâncias e caracteres, onde também o colete pode recortar uma trajetória de sentido peculiar e absolutamente atual.

0 paradoxo da moda reside, de fato, aqui - forte no nível do instante, a significação tende a se desfazer no nível da duração, sem, entretanto, romper-se definitivamente, simplesmente recua. Como toda estrutura significante, o sistema da moda é uma reserva ordenada de signos. Um ponto que implica a mobilização de um determinado tempo. De fato, o sistema é uma memória: oferece à permanência e à duração alguns fragmentos de substância, confinando algo no inatual ou atualizando uma lembrança. No que diz respeito a este, o signo do passado, atualizado no presente, muda porém de identidade: é, agora, um signo que carrega toda a memória da viajem que fez para chegar até nós. No caso particular do colete, assiste-se, ainda, a 
uma espécie de ondulação diacrônica, a um deslizar de um sistema para o outro, de um traje tipicamente masculino a um traje feminino. E assim, essa vestimenta não só teve um destino transestético, transcultural, transsocial, mas tornou-se também felizmente transsexual.

Os signos, antes de mudar de sentido, mudam de entornos, ou melhor, mudando suas relações, mudam de sentido. Dissemos que nenhum elemento detém sozinho 0 sentido. De alguma forma, todos são parasitários em relação aos outros: o sentido nasce não de um ou do outro, mas de sua associação. Portanto, vestir um colete sobre uma roupa moderna significa transformar seu sentido. No entanto, o colete retroage, ao mesmo tempo, sobre a vestimenta atual - irradiando sentido, cria o seu contesto. $\dot{E}$ a força do parcial inatual que modifica não somente o parecer, mas também o ser. $0 u_{\text {, }}$ agindo como simples indício ou como gesto mancado que surtiu seu efeito, limita-se, discretamente, a revelá-lo.

0 colete, de fato, participa daquilo que Barthes (1967) chama "a evidência do que está sob". É aquele interno que irresistivelmente tende para o externo, mostrando-se, quer parcialmente - no pescoço, nos pulsos, na parte dianteira do tronco -, quer completamente, quando uma peça que foi, por um tempo, considerada interna toma o lugar de uma peça externa, como acontece na moda feminina ou com o suéter. Esse segundo caso, como afirma Barthes, é sem dúvida menos interessante que o primeiro, pois

0 que vale esteticamente ou eroticamente é a mistura suspendida de evidente e de escondido que a variante de emergência tem que fazer significar. A emergência teria, em suma, a função de fazer ver o escondido sem, porém, destruir seu caráter secreto: desta forma, preserva-se a ambivalência fundamental da vestimenta (...) afinal, a vestimenta teria a ambiguidade de uma nevrose: podemos compará-lo com o rubor pudico que invade o rosto, como o signo paradoxal do segredo (BARTHES, 1967, p. 157).

\section{NOTAS}

[1] Tradução: Paolo Demuru.

${ }^{[2]} \mathrm{Na}$ Itália, o colete, além de panciotto, também era chamado de veste.

${ }^{[3]} 0$ termo francês gilet deriva do turco yelek.

${ }^{[4]}$ Pequena tira de tecido horizontal, normalmente presa por um botão, comum em calças, blazers, sobretudos, casacos e camisas.
}

${ }^{[5]}$ Veja: 0 colete azul em Max Beckmann, Autorretrato de clown (1921), Wuppertal, Von der Heydt Museum; e o autorretrato, sempre com o colete de gola azul, de James Ensor, Meu retrato com máscaras (1936), Bruxelas, coleção privada.

${ }^{\left[{ }^{6}\right]} 0$ colete ocupa um lugar importante entre as librés dos empregados domésticos, às quais, em 1913, a Gazette du Bon Ton dedicava um capitulo inteiro. Afirma-se aqui que o garçom que servia a mesa devia vestir fraque, calças de algodão e colete listrado.

${ }^{[7]} \mathrm{O}$ fato do colete ser ainda considerado o símbolo do vestuário burguês encontra-se confirmado na canção dos soldados paraquedistas italianos: "Se eu tivesse ficado em casa/lá na minha Lucera/teria hoje uma mulher gorda, alguns filhos e seria gordo também/Teria uma mulher gorda, as prestacões para pagar/o médico de família e um Seicento [carro popular da Fiat]/Um televisor, um colete e queixo duplo/ Mas eu fui dar volta no mundo/lá pelo mundo/E agora estou morrendo, aqui no Baixo Congo". 
${ }^{[8]}$ Citando apenas alguns exemplos, veja: de Max Beckmann, Retrato de um Argentino (1929), Munique, Staatsgemäldesammlungen; Retrato de Max Reger (1917), Zurique, Kunsthaus; de Manet, Le bon Bock (1873), The Philadelphia Museum of Art. Veja também os gaúchos dos filmes de Sergio Leone. De Lovis Corinth, além de seus autorretratos com colete, veja: Retrato do pianista Conrad Ansorge (1903), Munique, Städliche Galerie em Lenbachhaus; Autorretrato com modelo (1901), Winterthur, Kunstmuseum Winterthur; Retrato do pintor Karl Strathmann (1895), Munique, Städliche Galerie im Lenbachhaus; Retrato do pai com copo de vinho (1883), Munique, Städliche Galerie im Lenbachhaus. De Otto Dix, Retrato do filósofo Max Scheler, (1926), Köln, Philosophische Facultät; Retrato do Dr. Heinrich Stadelman (1922), Toronto, Art Gallery of Ontario; Retrato dos pais // (1924), Hannover, Niedersächsische Landsgalerie. De Georg Grosz, veja: Retrato do escritor Walter Mehring (1925), Antúerpia, Koninkljik Museum voor Schone Kunsten; Retrato do escritor Max Herrmann-Neisse (1925), Manheim, Städtische Kunsthalle. Impecáveis, a esse propósito, os coletes brancos de John Singer Sargent, como Retrato do pintor William Merrit Chase (1902), Nova York, The Metropolitan Museum of Art; Retrato de Lord Ribblesdale (1902), Londres, National Gallery; Retrato de Coventry Patmore (1894), Londres, National Portrait Gallery; Retrato de Sir Philip Sassoon (1923), Londres, Tate Gallery. Merecem também destaque os coletes de Joaquin Sorolla, Retrato de Aureliano de Beruete y Moret (1902), Madri, Museu do Prado; Retrato de Don José Echegaray (1905), Madri, Banca de España, como também os colete dos camponeses de Zuloaga, como Quatro bebedores (1905), Berlim, Staatliche Museen zu Berlin; A merenda (1899), Bilbao, coleção privada. Arnold Böcklin, entre uma visão onírica e a outra, retratando tranquilos burgueses de seu tempo, pinta coletes elegantíssimos, como aquele do Retrato do cantor Karl Wallenreiter (1861), Berlim, Staatliche Museen, Nationalgalerie. Além disso, veja os coletes vermelhos dos aristocratas de cavalo de Jacques-Laurent Agasse como, por exemplo, Retrato de Lord Rivers (1818), Genebra, Musée d'art et d'histoire. Vermelhos são também os coletes dos rapazes pintados por Paul Cézanne, mas, em particular, são importantes os coletes de Goya. Para Goya, o homem, seja aristocrata, burguês, camponês patriota, toureiro ou menino, veste sempre o colete e enfia a mão em seus bolsos, como em Retrato de Andrés del Peral (1797-1798), Londres, National Gallery; Retrato de Francisco de Cabarrús (1788), Madri, Banco de España e, em particular o fantástico colete amarelo do Retrato de Carlo III (1787), Madri, Museu do Prado.

${ }^{[9]}$ Veja, por exemplo, as mãos no colete nos retratos de Thomas Gainsborough, como: Retrato de um capitão holandês de um navio (1755-1758), desenho, Edimburgo, The Trustees of the National Gallery of Scotland; Retrato de Philippe Jacques de Loutherbourgh (1778), Londres, The Trustees of the Dulwhich Picture Gallery; Retrato de Abel Moysey (1771), Inglaterra, coleção privada, parte do acervo permanente da Gainsborough House, Sudbury; $O$ general James Johnson (1763-1764), Dublin, National Gallery; Autorretrato (1758-1759), Londres, The Trustees of the Dulwhich Picture Gallery; ou, como apontamos anteriormente, os retratos de Goya.

\section{REFERÊNCIAS}

ABRUZZESE, A. Essere moda: Appunti sui modi di affermarsi nel mondo ovvero sul mercato delle identità. In: ABRUZZESE, A.; BARILE, N. (Org.). Communifashion: sulla moda, della comunicazione. Roma: Sossella, 2001.

BALZAC, H. de. Eugénie Grandet. La Bibliothèque électronique du Québec. Disponivel em: <http://beq.ebooksgratuits.com/balzac/Balzac-26.pdf>. Acesso em: 15 jul. 2013.

BARTHES, R. Système de la mode. Paris: Seuil, 1967

CAROLL, L. Le avventure di Alice nel Paese delle Meraviglie: attraverso lo specchio. Milão: Mondatori, 2012.

DELEDDA, G. La giumenta nera. In: Novelle, v. 2. Disponivel em:

$<$ <ttp://www.sardegnadigitallibraryit/documenti/17_59_20080903124153.pdf>. Acesso em: 15 jul. 2013.

FLÜGEL, J. C. The psychology of clothes. Londres: Hogarth Press, 1950.

GOETHE, J. W. I dolori del Giovane Werther. Milão: Rizzole, 1995.

JAKOBSON, R. Essais de linguistique générale. Paris: Minuit, 1966.

ORLANDO, F. Gli oggetti desueti nelle immagini della letteratura: rovine reliquie, rarità, robaccia, luoghi inabitati e tesori nascosti. Turim: Einaudi, 1993.

SVEVO, I. La coscienza di Zeno. Milão: Feltrinelli, 1993

SWIFT, J. I viaggi di Gulliver. Milão: Feltrinelli, 1997. 